\title{
Cost of Self-Monitoring of Blood Glucose in the United States Among Patients on an Insulin Regimen for Diabetes
}

\author{
Jason Yeaw, MPH; Won Chan Lee, PhD; Mark Aagren, MSc; and Torsten Christensen, PhD
}

\begin{abstract}
BACKGROUND: People with diabetes are at an increased risk of developing numerous complications, resulting in increased health care expenditures, economic burden, and higher mortality. For patients using an insulin pump or multiple insulin injections, self-monitoring of blood glucose (SMBG) is recognized as a core component of effective diabetes self-management. However, little is known about the real-world frequency and true costs associated with SMBG as a percentage of an insulin regimen in the United States.

OBJECTIVE: To evaluate SMBG frequency, SMBG-related costs (including blood glucose test strips and testing supplies), and insulin therapy costs among insulin-dependent patients with diabetes and at least 1 pharmacy claim for blood glucose testing strips during a 12-month follow-up period.
\end{abstract}

METHODS: A retrospective database analysis was conducted using the IMS LifeLink Health Plan Claims database to capture the frequency and costs associated with SMBG in relation to a specific insulin regimen, and SMBG expenditure compared with other treatment costs. The study employed a retrospective cohort analysis of patients with 2 or more claims for insulin between January 1, 2007, and June 30, 2009, with the first such claim representing the index date. All patients were required to have 6 months of pre-index continuous enrollment (pre-index period) and 12 months of post-index continuous enrollment (follow-up period). Patients were also required to have a diagnosis of diabetes in the pre-index period and to have no gaps of more than 90 days between consecutive insulin claims during the 360-day follow-up period. Patients without at least 1 pharmacy claim for blood glucose testing strips during the 12-month follow-up period and patients with pharmacy claims with extreme values (greater than 1,500 strips) were excluded. Depending on the insulin types used within the 30 days immediately following their index date, patients were subcategorized into 1 of 4 insulin regimen groups (basal, bolus, premixed, or basal-bolus). Patients' frequency of blood glucose testing was measured throughout their 12-month post-index follow-up period through analysis of clinical codes found on pharmacy claims. Quantity supplied fields on pharmacy claims were used to calculate total tests utilized over the follow-up period (e.g., 50 test strips dispensed $=50$ tests assumed). Insulin-related costs were also evaluated for the 12-month follow-up period.

RESULTS: Among an initial sample of 373,946 patients with at least 2 claims for insulin between January 1, 2007, and June 30, 2009, 45,555 patients $(12.2 \%)$ formed the final overall cohort who met the inclusion and exclusion criteria. SMBG-related pharmacy costs accounted for $27 \%$ of the insulin- and SMBG-related treatment costs for insulin users with an average $\$ 772$ per patient in prescription testing strips and supplies versus $\$ 2,078$ for insulin prescriptions and supplies. With an overall mean utilization for pharmacy-based SMBG testing of 764.3 strips per year, the average cost per testing strip was $\$ 0.98$. Annual SMBG costs were $24.5 \%$ of total insulin and SMBG-related pharmacy costs for the basal insulin group compared with $35.8 \%$ for bolus, $21.0 \%$ for premixed, and $26.4 \%$ for basalbolus.

CONCLUSION: For insulin users with at least 1 pharmacy claim for glucose test strips, SMBG-related costs accounted for about one-fourth of total insulin and SMBG-related pharmacy costs.

J Manag Care Pharm. 2012;18(1):21-32

Copyright $\odot 2012$, Academy of Managed Care Pharmacy. All rights reserved.

\section{What is already known about this subject}

- Self-monitoring of blood glucose (SMBG) is recognized as a core component of effective diabetes self-management among patients using insulin pumps or multiple insulin injections by organizations such as the American Diabetes Association.

- The real-world frequency and true costs associated with SMBG as a percentage of a diabetes regimen or as compared with other diabetes treatment costs in the United States has not been previously studied.

\section{What this study adds}

- This study represents a novel attempt to measure the cost of SMBG relative to total treatment costs among insulin-dependent patients with diabetes.

- In this analysis of patients with at least 1 pharmacy claim for glucose testing strips, annual blood glucose testing costs equaled $24.5 \%$ of total insulin- and SMBG-related costs for the basal insulin group, compared with $35.8 \%$ for bolus, $21.0 \%$ for premixed, and $26.4 \%$ for basal-bolus.

- This study provides nationally representative SMBG testing information for commercially insured individuals and evaluates the potential economic burden of testing among diabetic insulin users.

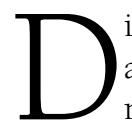
iabetes is recognized by the World Health Organization and the International Diabetes Federation as a significant and growing health problem. An estimated 285 million adults suffered from diabetes worldwide in 2010, and this number is expected to rise to 438 million by 2030. ${ }^{1}$ People with diabetes are at an increased risk of developing numerous complications, resulting in increased health care expenditures, economic burden, and higher mortality. Global expenditures for diabetes care are estimated to exceed $\$ 465$ billion in 2011 . $^{2}$ Not surprisingly, there is a large disproportion in spending for diabetes care by country and region. The United States accounts for more than $43 \%$ of global spending on diabetes care and is projected to spend $\$ 201$ billion in $2011 .^{2}$ 
An important part of the multipronged approach used to manage diabetes is adequate glycemic control, which is instrumental in preventing or delaying the complications associated with diabetes, such as peripheral vascular disease, vision loss, and renal failure. ${ }^{3-5}$ The usual method for monitoring glycemic control is by measuring glycated hemoglobin, or Alc, which gives an average of the blood glucose over 3 months. However, the Alc value does not inform patients about their blood glucose on a day-to-day basis. Self-monitoring by testing for urinary glucose is one method of checking if blood glucose is high, although it lacks the accuracy of alternative methods. A more accurate measure can be obtained by blood testing, which is done by pricking the skin to get a drop of blood, putting that blood on a testing strip, and reading the result with a small meter. This testing can be done at different times of day, before or after meals, or before or after physical activity.

Self-monitoring of blood glucose (SMBG) in patients with diabetes who use insulin may contribute to improved glycemic control and reduced hypoglycemia by allowing for selfadjustments in insulin dose based on meter readings. ${ }^{4}$ SMBG is recognized as a core component of effective diabetes selfmanagement by organizations such as the American Diabetes Association (ADA). ${ }^{5-8}$ SMBG is currently recommended by the ADA 3 or more times daily for people with diabetes using multiple daily insulin injections or insulin pumps. ${ }^{6}$ Among patients with a lower frequency of insulin administration, medical nutrition monotherapy, or noninsulin treatments, ADA guidelines (2011) state that "SMBG may be useful as a guide to the success of therapy." ${ }^{6}$

Diabetes self-management, an important aspect of diabetes management, is one of the most challenging management regimens of any chronic illness. ${ }^{9}$ People with diabetes are asked to perform SMBG, manage multiple medications, maintain foot hygiene, adhere to diet and meal plans, and engage in an exercise program. ${ }^{10,11}$ SMBG exerts a significant burden in terms of patients' daily behavior ${ }^{12}$ and economic consequences. According to the ADA, the total economic burden of diabetes in the United States amounted to $\$ 174$ billion in 2007, or an average of $\$ 6,649$ per person with diabetes per year. ${ }^{13}$ Supplies and equipment (e.g., test strips and monitors) amounted to \$102 per person; in contrast, average insulin costs were $\$ 214$ for all diabetes patients and $\$ 751$ for insulin users only annually. As SMBG has gained acceptance as a key component of diabetes care around the world, some country-specific studies have addressed cost and utilization. ${ }^{14-17}$ However, little is known about the real-world frequency and true costs associated with SMBG as a percentage of a diabetes regimen or as compared with insulin-related pharmacy costs in the United States.

\section{Methods}

A retrospective database analysis was conducted using the IMS LifeLink Health Plan Claims database. The LifeLink Claims database comprises fully adjudicated medical and pharmaceutical claims for more than 75 million unique patients from more than 100 health plans across the United States (approximately 16 million covered lives per year) from January 1997 through December 2009. The database includes both inpatient and outpatient diagnoses (in International Classification of Diseases, Ninth Revision, Clinical Modification [ICD-9-CM] codes) and procedures (in Current Procedural Terminology, Fourth Edition [CPT-4] and Healthcare Common Procedure Coding System [HCPCS] codes), as well as retail and mail order pharmacy claim records. Available data on pharmacy claim records include the National Drug Code (NDC) and the MediSpan (Indianapolis, IN) generic product identifier (GPI) code, as well as the quantity of the medication dispensed. Amounts charged by providers and amounts allowed and paid by health plans are available for all services rendered, as well as dates of service for all claims. Allowed amounts were used in this study, representing the total reimbursable amount for specific services as negotiated between health plans and care providers, including patient cost-sharing amount. Additional data elements include demographic variables (age, gender, and geographic region), product type (e.g., health maintenance organization [HMO], preferred provider organization [PPO]), payer type (e.g., commercial, self-pay), provider specialty, and start and stop dates of health plan enrollment.

Records in the LifeLink U.S. claims database are generally representative of the national, commercially insured population in terms of age and gender. The data are also longitudinal, with an average duration of member enrollment of 2 years. Only health plans that submit data for all members are included in the database, ensuring complete data capture and representative samples. Data contributions are also subjected to a series of quality checks to ensure a standardized format and to minimize error rates.

The study employed a retrospective cohort analysis of data from July 1, 2006, through June 30, 2010 (study period), the most recent data available at the time of data extraction. All patients identified according to the methods defined below constituted the study sample. Depending on the insulin types used, patients were subcategorized into 1 of 4 insulin regimen groups (basal, bolus, premixed, or basal-bolus). The subcategories were created to differentiate the basal insulin regimen, which normally is titrated and monitored less frequently compared with basal/bolus, premixed, and bolus regimens, which also provide meal-time insulin coverage.

\section{Inclusion Criteria}

To be selected into the study sample, patients must have had at least 2 pharmacy claims for insulin (Appendix A) during the period from January 1, 2007, through June 30, 2009 (index window). The date of the first such claim for a patient during the index window was the index date. The study required that 


\section{FIGURE 1 Patient Selection Flowchart}

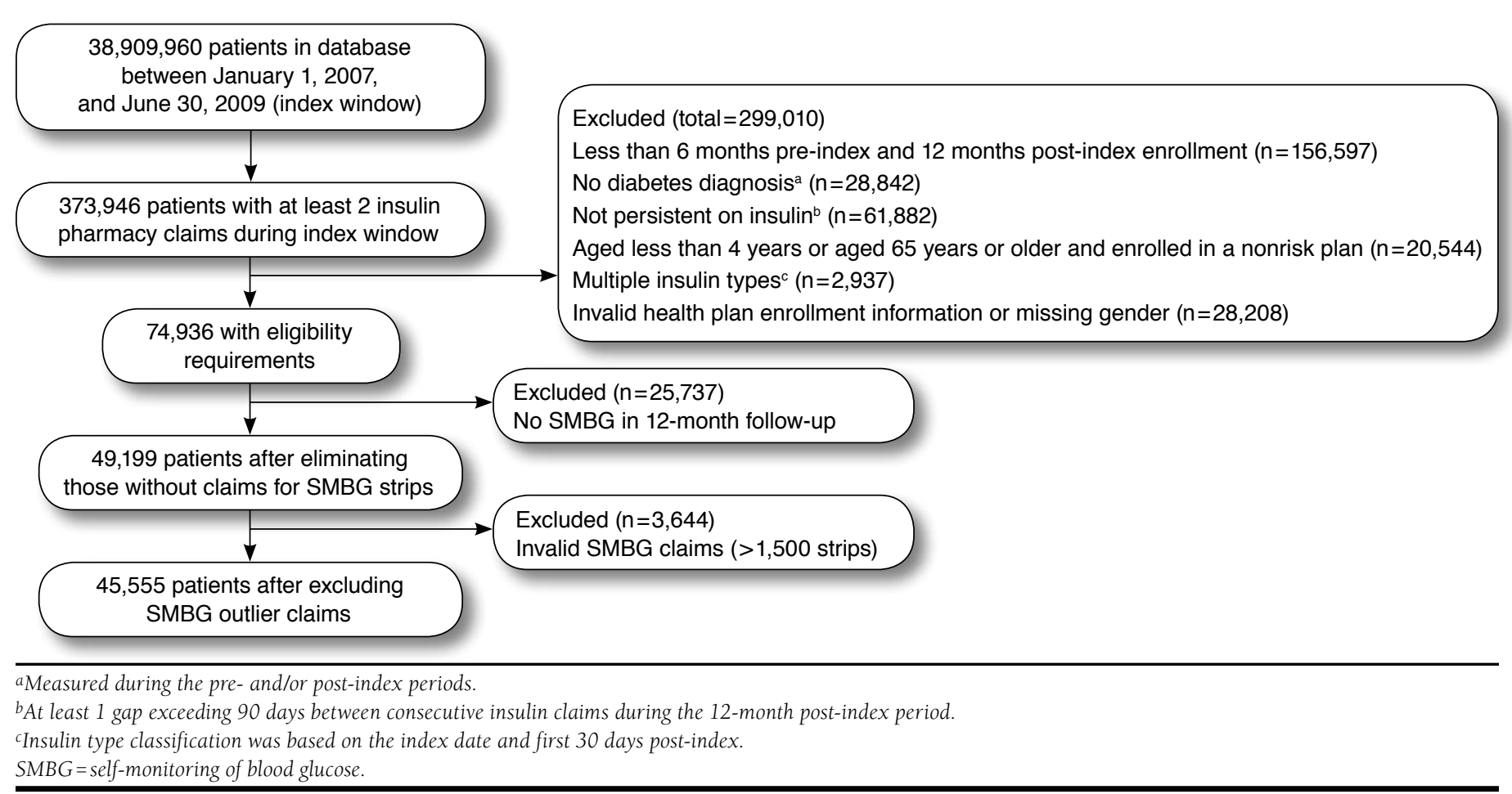

patients be continuously enrolled in their health plans for at least the most recent 6 months preceding the index date (preindex period) through at least 12 months following the index date (follow-up period). The pre-index period was used for describing baseline characteristics, with the exception of diabetes type, while the follow-up period was used for outcomes measurement. All patients must have had a combination of medical claims with a diagnosis for type 1 or type 2 diabetes mellitus (Appendix B) during the pre- and/or post-index period, as well as pharmacy claims for specific antidiabetic agents or insulin (Appendix A) in the 6-month pre-index period (Figure 1).

In order to further refine the cohort to include only patients for which SMBG would be expected and/or necessary, patients were required to have been persistent with insulin therapy throughout the 12-month follow-up period. A modified version of a persistence measure that has been previously used in insulin studies using claim databases was used. ${ }^{18}$ Specifically, patients were considered persistent with insulin if they did not have a gap exceeding 90 days between 2 consecutive insulin prescriptions at any time during the follow-up period.

\section{Exclusion Criteria}

Patients were excluded from the study sample if they were aged less than 4 years on their index date or were aged 65 years or older on their index date but were not enrolled in a Medicare risk plan, since claims histories may have been incomplete for these patients. Additionally, in order to decrease the risk of insulin type misclassification, patients with pharmacy claims for more than 1 insulin regimen (basal, premixed, basal-bolus, bolus only; see Appendix A) within the first 30 days immediately following the index date (including the index date) were excluded, with the exception of the basal-bolus group. For patients with an index pharmacy claim for either basal or bolus insulin, the 30 days immediately following the index date were evaluated for evidence of both basal and bolus therapy, with at least 1 pharmacy claim for the second insulin type being required for inclusion in the basal-bolus group. Among patients in the basal-bolus group, claims for premixed insulin within 30 days of the index date warranted patient exclusion.

Once categorized into 1 of 4 insulin regimen categories (basal, bolus, premixed, and basal-bolus), based on index pharmacy claims and all claims within 30 days following the index date (for basal-bolus determination only), patients were followed according to an intent-to-treat analysis. While persistence is partially accounted for by eliminating patients with gaps in therapy greater than 90 days in duration during the follow-up period, switching insulin types during the follow-up period (days 31 through 360 ) was not evaluated in this analysis. 


\section{Blood Glucose Testing Data Trimming}

The distribution of values for quantity supplied on blood glucose claims was analyzed for evidence of abnormalities. Patients collecting their SMBG strips over-the-counter (OTC) would have zero claims and thereby constitute potential underreporting, given the study requirement that patients be persistent on an insulin therapy throughout the study period. To reduce potential bias (under-/over-reporting), data trimming was applied. Patients with claims for quantities that were missing, zero, or greater than 1,500 strips per claim were excluded from the analysis of blood glucose testing.

\section{Measurements}

All of the following measures were provided for the overall insulin-dependent diabetes cohort as well as for the 4 specific subsets of insulin regimens.

Baseline Patient Demographics and Clinical Characteristics. The following patient demographic characteristics were measured as of the patient's index date or during his/her 6-month pre-index period: gender; age group in years (4-17, 18-34, $35-54,55-64$, or 65 or older) as of the index date; type of diabetes mellitus (type 1 or type 2); type of insulin used within the first 30 days immediately following the index date (Appendix A); type of health plan (HMO, PPO, point of service [POS], indemnity, consumer-directed, or other/unknown); type of payer (commercial, Medicare risk, self-insured, Medicaid, or unknown); geographic region of the health plan (Northeast, South, Midwest, or West); total health care costs for all conditions during the patient's 6-month pre-index period, not including the index date, as a broad severity measure; insulin naive or continuing insulin therapy, based on the presence of any insulin products in the pre-index period; and Charlson Comorbidity Index (CCI) score (Dartmouth-Manitoba adaptation). ${ }^{19}$

The study sample was described in terms of the patient's baseline demographic and clinical characteristics, using frequency and percentage distributions for categorical variables and descriptive statistics (mean, standard deviation [SD], and median) for continuous and count variables.

Blood Glucose Testing. The frequency of blood glucose testing was captured throughout the 12-month post-index follow-up period through analysis of clinical codes found on medical and pharmacy claims (Appendix A).

The primary means for measuring SMBG included the identification of health plan claims for blood glucose testing strips at a retail or mail pharmacy (GPI codes 94100030006100 , 94100030009800, or 94100030006000) or through medical claims (HCPCS code A4253). A prescription for blood glucose testing strips is typically required for coverage by a patient's health insurance plan, and many insurance companies, including Medicare, pay for these supplies. Blood glucose testing also included visits to an outpatient clinic or laboratory/diagnostic center with a procedure code for blood glucose testing (see Appendix A for CPT-4 codes ) excluding panel tests (e.g., basic metabolic panel, 80048).

The quantities supplied of blood glucose strips through pharmacy or medical claims were used to assess utilization. A pharmacy claim with a quantity of 50 blood glucose testing strips was counted as 50 tests, based on the quantity field on the claim, while each claim for outpatient procedures and lab procedures was counted as 1 incident of blood glucose testing. In other words, 1 visit to an outpatient facility or a laboratory/ diagnostic facility for a blood glucose test was counted as 1 test.

The frequency of blood glucose testing was described using descriptive statistics (mean, SD). Furthermore, frequency of blood glucose testing was stratified by diabetes type (type 1 or type 2), and descriptive statistics (mean, SD) were provided for each stratum.

Health Care Utilization and Costs. Total insulin-related and SMBG-related pharmacy costs during the 12-month followup period were of primary interest and included those costs specifically attributable to (a) blood glucose testing (including blood glucose strips, lancets, meters) and (b) insulin therapy and supplies (syringes, needles; see Appendix A). Of secondary interest, specific all-cause component costs were assessed and included the following specific categories: noninsulin-related pharmacy (including all drugs, not just diabetes-related drugs); outpatient care; emergency room visits; physician office visits (primary care provider, family practitioner, general practitioner, internal medicine, endocrinology, and other/unknown); outpatient blood glucose testing procedures; laboratory and radiology tests; outpatient ancillary; and inpatient care. Costs associated with inpatient care were identified by the presence of room and board-related facility revenue codes, while costs associated with outpatient services were identified by the presence of evaluation and management claim codes. Specific blood glucose testing costs as specified above were summed to a total cost, as were costs specifically related to insulin therapy.

Costs were based on the amount allowed by the patient's health plan and were inflation-adjusted to 2010 prices using the medical care component of the U.S. Consumer Price Index for All Urban Consumers. ${ }^{20}$ All analyses were performed using SAS (SAS Institute Inc., Cary, NC) version 9.2 and an a priori alpha of 0.05 .

\section{Results}

\section{Demographics and Clinical Characteristics}

Among an initial sample of 373,946 patients with at least 1 claim for insulin between January 1, 2007, and June 30, $2009,74,936(20.0 \%)$ met all of the aforementioned inclusion and exclusion criteria to be included in the study. After removing patients without glucose test strip claims in the 


\section{TABLE 1 Baseline Characteristics of the Study Sample by Insulin Regimen}

\begin{tabular}{|c|c|c|c|c|c|c|c|c|}
\hline \multirow[b]{2}{*}{ Characteristic } & \multirow[b]{2}{*}{$\begin{array}{l}\text { All Patients } \\
(\mathrm{n}=45,555)\end{array}$} & \multicolumn{7}{|c|}{ Index Insulin Therapy } \\
\hline & & $\begin{array}{c}\text { Basal } \\
(\mathrm{n}=17,990)\end{array}$ & $\begin{array}{c}\text { Bolus } \\
(\mathbf{n}=7,755)\end{array}$ & $\begin{array}{l}P \text { Valuea } \\
\text { vs. Basal }\end{array}$ & $\begin{array}{l}\text { Premixed } \\
(\mathrm{n}=5,468)\end{array}$ & $\begin{array}{l}P \text { Value }^{\mathrm{a}} \\
\text { vs. Basal }\end{array}$ & $\begin{array}{c}\text { Basal-Bolus } \\
\text { Combination } \\
(n=14,342)\end{array}$ & $\begin{array}{l}P \text { Value } \\
\text { vs. Basal }\end{array}$ \\
\hline \multicolumn{9}{|l|}{ Age (years) } \\
\hline Mean & 51.2 & 55.3 & 43.7 & & 58.4 & & 47.3 & \\
\hline $\mathrm{SD}$ & 16.5 & 12.7 & 18.4 & & 12.5 & & 18.2 & \\
\hline Median & 54 & 57 & 47 & $<0.001$ & 59 & $<0.001$ & 52 & $<0.001$ \\
\hline \multicolumn{9}{|l|}{ Age group (n, \%) } \\
\hline 4-17 years & $2,950 \quad 6.5$ & $295 \quad 1.6$ & $1,011 \quad 13.0$ & $<0.001$ & $23 \quad 0.4$ & $<0.001$ & $1,621 \quad 11.3$ & $<0.001$ \\
\hline $18-34$ years & $3,813 \quad 8.4$ & $719 \quad 4.0$ & $1,313 \quad 16.9$ & & $175 \quad 3.2$ & & $1,606 \quad 11.2$ & \\
\hline $35-54$ years & $16,031 \quad 35.2$ & $6,49636.1$ & $2,869 \quad 37.0$ & & $1,65730.3$ & & $5,00934.9$ & \\
\hline $55-64$ years & $15,843 \quad 34.8$ & $7,36540.9$ & $1,84923.8$ & & $2,20740.4$ & & $4,42230.8$ & \\
\hline $65+$ years & $6,918 \quad 15.2$ & $3,115 \quad 17.3$ & $713 \quad 9.2$ & & $1,40625.7$ & & $1,684 \quad 11.7$ & \\
\hline \multicolumn{9}{|l|}{ Gender (n, \%) } \\
\hline Female & $21,89748.1$ & $8,66748.2$ & $3,980 \quad 51.3$ & $<0.001$ & $2,70749.5$ & 0.085 & $6,54345.6$ & $<0.001$ \\
\hline Male & $23,658 \quad 51.9$ & $9,32351.8$ & $3,77548.7$ & & $2,761 \quad 50.5$ & & $7,79954.4$ & \\
\hline \multicolumn{9}{|l|}{ Payer type (n, \%) } \\
\hline Commercial & $37,60682.6$ & $14,50680.6$ & $6,90289.0$ & $<0.001$ & $4,03573.8$ & $<0.001$ & $12,163 \quad 84.8$ & $<0.001$ \\
\hline Medicaid & $1,435 \quad 3.2$ & $456 \quad 2.5$ & $141 \quad 1.8$ & & $225 \quad 4.1$ & & $\begin{array}{ll}613 & 4.3 \\
\end{array}$ & \\
\hline Medicare risk & $2,349 \quad 5.2$ & $984 \quad 5.5$ & $239 \quad 3.1$ & & 57810.6 & & $548 \quad 3.8$ & \\
\hline Self-insured & $4,100 \quad 9.0$ & $2,007 \quad 11.2$ & $463 \quad 6.0$ & & $622 \quad 11.4$ & & $1,008 \quad 7.0$ & \\
\hline Unknown & $\begin{array}{ll}65 & 0.1 \\
\end{array}$ & $\begin{array}{ll}37 & 0.2 \\
\end{array}$ & $\begin{array}{ll}10 & 0.1 \\
\end{array}$ & & $\begin{array}{ll}8 & 0.1 \\
\end{array}$ & & $\begin{array}{ll}10 & 0.1 \\
\end{array}$ & \\
\hline \multicolumn{9}{|l|}{ Plan type (n, \%) } \\
\hline Consumer-directed & 1320.3 & \begin{tabular}{ll|}
39 & 0.2 \\
\end{tabular} & $\begin{array}{ll}20 & 0.3 \\
\end{array}$ & 0.006 & $\begin{array}{ll}17 & 0.3 \\
\end{array}$ & $<0.001$ & $\begin{array}{ll}56 & 0.4 \\
\end{array}$ & $<0.001$ \\
\hline $\mathrm{HMO}$ & $9,968 \quad 21.9$ & $3,873 \quad 21.5$ & $1,527 \quad 19.7$ & & $1,395 \quad 25.5$ & & $3,173 \quad 22.1$ & \\
\hline Indemnity & $2,847 \quad 6.2$ & $1,084 \quad 6.0$ & $\begin{array}{lll}451 \quad 5.8 \\
\end{array}$ & & $419 \quad 7.7$ & & $893 \quad 6.2$ & \\
\hline $\mathrm{PPO}$ & $26,159 \quad 57.4$ & $10,54958.6$ & $4,628 \quad 59.7$ & & $3,052 \quad 55.8$ & & $7,930 \quad 55.3$ & \\
\hline POS & $5,891 \quad 12.9$ & $2,198 \quad 12.2$ & $1,032 \quad 13.3$ & & $527 \quad 9.6$ & & $2,134 \quad 14.9$ & \\
\hline Unknown & $\begin{array}{ll}558 & 1.2 \\
\end{array}$ & $247 \quad 1.4$ & $\begin{array}{ll}97 & 1.3 \\
\end{array}$ & & $\begin{array}{ll}58 & 1.1 \\
\end{array}$ & & $\begin{array}{ll}156 & 1.1 \\
\end{array}$ & \\
\hline \multicolumn{9}{|l|}{ Region (n, \%) } \\
\hline Northeast & $11,44725.1$ & $5,008 \quad 27.8$ & $1,69021.8$ & $<0.001$ & $1,526 \quad 27.9$ & $<0.001$ & $3,22322.5$ & $<0.001$ \\
\hline Midwest & $15,15233.3$ & $5,448 \quad 30.3$ & $2,71935.1$ & & $1,517 \quad 27.7$ & & $5,46838.1$ & \\
\hline South & $11,49125.2$ & $4,668 \quad 25.9$ & $2,06626.6$ & & $1,651 \quad 30.2$ & & $3,106 \quad 21.7$ & \\
\hline West & $7,465 \quad 16.4$ & $2,866 \quad 15.9$ & $1,280 \quad 16.5$ & & $774 \quad 14.2$ & & $2,545 \quad 17.7$ & \\
\hline \multicolumn{9}{|l|}{ Diabetes typeb (n, \%) $^{\text {b }}$} \\
\hline Type 1 & $18,42140.4$ & $3,428 \quad 19.1$ & $5,51271.1$ & $<0.001$ & $1,610 \quad 29.4$ & $<0.001$ & $7,87154.9$ & $<0.001$ \\
\hline Type 2 & $27,13459.6$ & $14,56280.9$ & $2,24328.9$ & & $3,85870.6$ & & $6,471 \quad 45.1$ & \\
\hline New to insulin therapy $(n, \%)$ & $19,05141.8$ & $9,60653.4$ & $2,150 \quad 27.7$ & $<0.001$ & $2,066 \quad 37.8$ & $<0.001$ & $5,22936.5$ & $<0.001$ \\
\hline \multicolumn{9}{|l|}{ Charlson comorbidity burden } \\
\hline Mean & 2.0 & 2.0 & 2.1 & & 2.1 & & 2.0 & \\
\hline SD & 1.5 & 1.5 & 1.4 & & 1.6 & & 1.5 & \\
\hline Median & 2 & 1 & 2 & - & 2 & - & 1 & - \\
\hline 0 & $659 \quad 1.4$ & $327 \quad 1.8$ & $37 \quad 0.5$ & $<0.001$ & $84 \quad 1.5$ & $<0.001$ & $211 \quad 1.5$ & 0.007 \\
\hline 1 & $21,28046.7$ & $9,02850.2$ & $2,79836.1$ & & $2,42844.4$ & & $7,02649.0$ & \\
\hline 2 & $12,74428.0$ & $4,418 \quad 24.6$ & $3,285 \quad 42.4$ & & $1,38325.3$ & & $3,658 \quad 25.5$ & \\
\hline $3+$ & $10,87223.9$ & $4,21723.4$ & $1,63521.1$ & & $1,57328.8$ & & $3,447 \quad 24.0$ & \\
\hline \multicolumn{9}{|l|}{ Total pre-index medical costs } \\
\hline Mean & $\$ 12,610$ & $\$ 11,218$ & $\$ 13,021$ & & $\$ 10,251$ & & $\$ 15,032$ & \\
\hline SD & $\$ 31,354$ & $\$ 26,860$ & $\$ 30,583$ & & $\$ 20,415$ & & $\$ 39,277$ & \\
\hline Median & $\$ 4,732$ & $\$ 4,297$ & $\$ 5,239$ & $<0.001$ & $\$ 4,491$ & 0.070 & $\$ 5,155$ & $<0.001$ \\
\hline
\end{tabular}




\section{FIGURE 2 12-Month Mean Number [SD] of Pharmacy-Based Blood Glucose Tests for Patients with Plan-Covered Test Strip Use $^{\mathrm{a}}$ by Index Insulin Regimen ${ }^{\mathrm{b}}$}

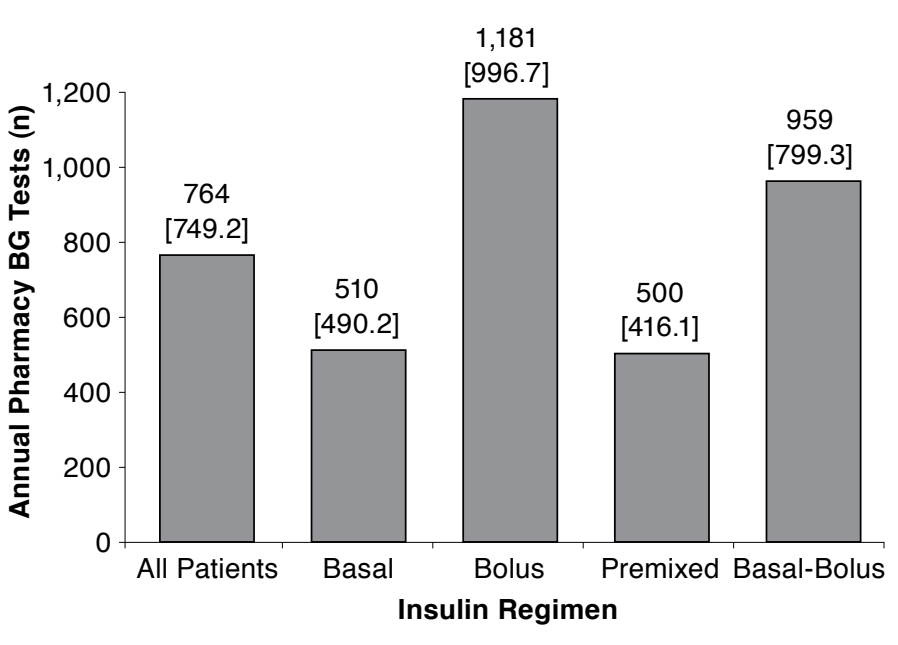

abased on total quantity supplied (e.g., a pharmacy claim for 50 test strips counted as 50 blood glucose tests). Limited to patients with at least 1 pharmacy claim for test strips during the 12-month follow-up period.

'Insulin type classification was based on the first 30 days post-index. $B G=$ blood glucose $; S D=$ standard deviation.

12-month follow-up period, the final overall cohort was 45,555 patients (12.2\%; Figure 1).

Categorization by initial insulin regimen resulted in the following insulin-specific subgroups for analysis: 17,990 (39.5\%) on basal insulin, 7,755 (17.0\%) on bolus insulin, 5,468 (12.0\%) on premixed insulin, and $14,342(31.5 \%)$ on basalbolus combination insulin.

All baseline characteristics of the basal insulin group were significantly different from characteristics of the other 3 insulin groups, when compared pair-wise. However, results should be viewed with some degree of caution, as some significant results may be influenced by a larger proportion of persons with type 1 diabetes in the basal-bolus and bolus only group.

Patients in the basal insulin group were significantly older than patients in both the bolus and basal-bolus insulin groups, with an average age of 55.3 years, compared with 43.7 years for bolus and 47.3 years for basal-bolus $(P<0.001$; Table 1$)$. The proportion of women in the overall cohort was 48.1, ranging from 45.6 in the basal-bolus group to 51.3 in the bolus group. Compared with other insulin groups, a lower proportion $(P<0.001)$ of basal patients had type 1 diabetes, $19.1 \%$ versus $71.1 \%$ for bolus, $29.4 \%$ for premixed, and $54.9 \%$ for basalbolus. A higher proportion of patients on basal insulin were new to insulin therapy, 53.4\%, compared with other insulin regimens $(27.7 \%$ for bolus, $37.8 \%$ for premixed, and $36.5 \%$ for basal-bolus). Mean (SD) total all-cause pre-index (6-month) medical costs ranged from $\$ 10,251(\$ 20,415)$ for premixed to $\$ 15,032(\$ 39,277)$ for basal-bolus, with an overall cohort average of $\$ 12,610(\$ 31,354)$.

\section{Blood Glucose Testing}

Among patients with at least 1 pharmacy claim for blood glucose testing strips, the overall mean number of pharmacybased blood glucose tests in the follow-up period was 764.3, ranging from 500.0 tests in the premixed group to $1,180.9$ in the bolus group (Figure 2). Patients using premixed insulin had a small but significantly lower number of blood glucose tests (500.0) compared with patients on a basal regimen (510.5, $P<0.001$ ). Patients on a basal regimen had a significantly lower number of blood glucose tests compared with patients using bolus insulin $(1,180.9, P<0.001)$ and patients on a basal-bolus regimen (959.0, $P<0.001$ ). Persons with type 1 diabetes had a significantly higher number of blood glucose tests (1,096.9 vs. 538.6, $P<0.001)$ compared with persons with type 2 diabetes (data not shown). With the vast majority of plan-covered blood glucose testing being pharmacy based, the mean number of outpatient tests and medical tests in the overall cohort were 0.6 and 0.1, respectively, during the 1-year follow-up period.

\section{Health Care Utilization}

Over the 1-year follow-up period, basal insulin patients had 9.3 pharmacy claims for insulin, compared with 9.3 claims for the bolus group, 9.8 for the premixed group, and 15.3 for the basalbolus group (data not shown). Compared with each of the other insulin groups, basal patients had a significantly higher number of oral antidiabetic claims, 8.8 prescriptions compared with 2.3 for bolus $(P<0.001), 5.6$ for premixed $(P<0.001)$, and 3.2 for basal-bolus $(P<0.001$, data not shown). A significantly higher proportion of patients with basal insulin had at least 1 hospitalization over the l-year follow-up period compared with both the premixed group and the basal-bolus group (18.1\% for basal, $20.8 \%$ for both premixed and basal-bolus, $P<0.001$, data not shown).

\section{Health Care Costs}

For the overall cohort, the average cost for pharmacy-related blood glucose testing was $\$ 772$ (and $\$ 787$ when including outpatient and laboratory tests) over the 1-year follow-up period (Table 2). With an overall mean utilization for pharmacy-based blood glucose testing of 764.3 strips per year, the average cost per testing strip was $\$ 0.98$. The overall cohort had an average annual pharmacy cost of $\$ 2,078$ attributable to insulin and insulin-related administration supplies, yielding a total of $\$ 2,850(\$ 722+\$ 2,078)$ for insulin and SMBG-related pharmacy costs. Annual blood glucose testing costs equaled $24.5 \%$ of total insulin and SMBG-related costs for the basal insulin group, compared with $35.8 \%$ for bolus, $21.0 \%$ for premixed, and $26.4 \%$ for basal-bolus (Figure 3). 


\section{TABLE 2 Mean All-Cause Health Care Services Costs (\$) by Insulin Regimen Type}

\begin{tabular}{|c|c|c|c|c|c|c|c|c|c|c|}
\hline \multirow[b]{3}{*}{ Characteristic } & & & & \multicolumn{7}{|c|}{ Index Insulin Therapy } \\
\hline & \multicolumn{3}{|c|}{$\begin{array}{l}\text { All Patients } \\
(\mathrm{n}=45,555)\end{array}$} & \multicolumn{3}{|c|}{$\begin{array}{c}\text { Basal } \\
(n=17,990)\end{array}$} & \multicolumn{3}{|c|}{$\begin{array}{c}\text { Bolus } \\
(\mathbf{n}=7,755)\end{array}$} & \multirow{2}{*}{$\begin{array}{l}P \text { Value } \\
\text { vs. Basal }\end{array}$} \\
\hline & Mean & SD & Median & Mean & SD & Median & Mean & SD & Median & \\
\hline Total costs & 21,541 & 40,245 & 11,040 & 19,924 & 37,243 & 10,418 & 22,346 & 41,330 & 11,451 & $<0.001$ \\
\hline Total pharmacy costs & 7,413 & 9,982 & 5,375 & 7,056 & 9,883 & 5,245 & 7,410 & 10,501 & 5,093 & 0.485 \\
\hline Insulin-related costs & 2,078 & & & 1,609 & & & 2,083 & & & \\
\hline Basal & 916 & 1,061 & 729 & 1,217 & 1,167 & 1,031 & 250 & 547 & 0 & $<0.001$ \\
\hline Bolus & 821 & 1,157 & 333 & 245 & 581 & 0 & 1,734 & 1,388 & 1,622 & $<0.001$ \\
\hline Premixed & 214 & 752 & 0 & 41 & 281 & 0 & 14 & 178 & 0 & - \\
\hline Insulin administration supplies & 127 & 225 & 77 & 105 & 200 & 78 & 85 & 225 & 0 & $<0.001$ \\
\hline SMBG-related costs & 772 & & & 522 & & & 1,161 & & & \\
\hline BG testing strips & 750 & 741 & 519 & 505 & 491 & 373 & 1,140 & 983 & 925 & $<0.001$ \\
\hline Other BG testing supplies & 22 & 142 & 0 & 17 & 37 & 0 & 21 & 103 & 0 & - \\
\hline Insulin + SMBG-related costs & 2,850 & & & 2,131 & & & 3,244 & & & \\
\hline Oral antidiabetic medications & 491 & 912 & 28 & 791 & 1,098 & 255 & 206 & 637 & 0 & $<0.001$ \\
\hline Other NDC pharmacy & 3,306 & 5,318 & 1,822 & 3,404 & 4,898 & 2,134 & 2,998 & 5,412 & 1,253 & $<0.001$ \\
\hline Other HCPCS pharmacy & 766 & 7,488 & 0 & 731 & 7,641 & 0 & 961 & 8,258 & 0 & - \\
\hline Total outpatient costs & 8,127 & 18,285 & 3,794 & 7,394 & 16,783 & 3,448 & 9,163 & 17,909 & 4,746 & $<0.001$ \\
\hline Emergency room visits & 390 & 1,425 & 0 & 358 & 1,271 & 0 & 419 & 1,745 & 0 & - \\
\hline Insulin injections & 1 & 45 & 0 & 1 & 49 & 0 & 2 & 47 & 0 & - \\
\hline BG testing lab/clinics & 10 & 108 & 0 & 6 & 35 & 0 & 20 & 132 & 0 & - \\
\hline BG testing strips/supplies & 5 & 69 & 0 & 4 & 39 & 0 & 7 & 81 & 0 & - \\
\hline Insulin administration supplies & 391 & 1,429 & 0 & 85 & 721 & 0 & 1,436 & 2,256 & 512 & - \\
\hline Alc lab testing & 43 & 54 & 30 & 41 & 52 & 29 & 49 & 59 & 36 & $<0.001$ \\
\hline \multicolumn{11}{|l|}{ Outpatient management visits } \\
\hline FP/GP/Internal medicine & 409 & 1,558 & 249 & 444 & 2,020 & 297 & 323 & 984 & 163 & $<0.001$ \\
\hline Endocrinology & 128 & 251 & 0 & 99 & 232 & 0 & 175 & 267 & 0 & - \\
\hline Other/Unknown & 1,113 & 4,634 & 536 & 1,012 & 3,747 & 520 & 1,178 & 4,783 & 555 & $<0.001$ \\
\hline Laboratory and pathology & 574 & 1,741 & 231 & 535 & 1,575 & 226 & 614 & 1,612 & 245 & $<0.001$ \\
\hline Radiology & 972 & 3,834 & 123 & 981 & 4,124 & 141 & 978 & 4,382 & 83 & $<0.001$ \\
\hline Surgical services & 911 & 2,873 & 0 & 902 & 2,826 & 0 & 851 & 2,914 & 0 & - \\
\hline Ancillary services & 3,179 & 13,801 & 589 & 2,925 & 12,621 & 620 & 3,111 & 12,731 & 449 & $<0.001$ \\
\hline Total inpatient costs & 6,001 & 27,333 & 0 & 5,474 & 25,210 & 0 & 5,773 & 27,115 & 0 & - \\
\hline
\end{tabular}

apearson chi-square test for categorical variables; Wilcoxon rank-sum test for continuous and count variables.

Alc =hemoglobin $A 1 c ; B G=$ blood glucose; $F P=$ family practitioner; $G P=$ general practitioner; HCPCS=Healthcare Common Procedure Coding System; NDC=national drug code; $S D=$ standard deviation; $S M B G=$ self-monitoring of blood glucose.

\section{Discussion}

SMBG constituted a large part of the insulin and SMBG-related pharmacy costs for insulin users, with prescription testing strips and supplies totaling $27 \%$ of the cost of insulin prescriptions and supplies ( $\$ 772$ of $\$ 2,850$ ). While the total costs of insulin use in a population with diabetes are well studied, as are the proportion of total costs associated with insulin, the economic implications of SMBG for both payers and patients are not well understood and affect specific subgroups disproportionately. Most notably, among bolus insulin users, SMBG costs were $35.8 \%$ of insulin costs ( $\$ 1,161$ of $\$ 3,244)$, most likely due to higher use of insulin pumps in the category.

Compared with a 2007 ADA report on the economic cost of diabetes in the United States, which found per patient annual insulin costs of $\$ 751$, this study's finding of $\$ 1,951$ in insulin-related costs (excluding SMBG-related costs and insulin-administration supplies) is considerably higher, although the data sources and time frames for analysis differ greatly. ${ }^{13}$ Specifically, the ADA study used surveillance data (Medical Expenditure Panel Survey) from 2003-2005 adjusted to 2007 costs, while this study used health care claims data from 2007 to 2009. The ADA found an annual $\$ 102$ per patient cost attributable to diabetes supplies, compared with this study's $\$ 127$ in insulin administration supplies per year. It should be noted that the present study focused on insulin users only, while the ADA analysis included all diabetics. 


\section{TABLE 2 Mean All-Cause Health Care Services Costs (\$) by Insulin Regimen Type (continued)}

\begin{tabular}{|c|c|c|c|c|c|c|c|c|}
\hline \multirow[b]{3}{*}{ Characteristic } & \multicolumn{8}{|c|}{ Index Insulin Therapy } \\
\hline & \multicolumn{3}{|c|}{$\begin{array}{l}\text { Premixed } \\
(\mathrm{n}=5,468)\end{array}$} & \multirow{2}{*}{$\begin{array}{l}P \text { Value }^{\mathrm{a}} \\
\text { vs. Basal }\end{array}$} & \multicolumn{3}{|c|}{$\begin{array}{l}\text { Basal-Bolus Combination } \\
\qquad(\mathrm{n}=14,342)\end{array}$} & \multirow{2}{*}{$\begin{array}{l}P \text { Value } \\
\text { vs. Basal }\end{array}$} \\
\hline & Mean & SD & Median & & Mean & SD & Median & \\
\hline Total costs & 21,572 & 39,066 & 10,869 & 0.020 & 23,121 & 43,512 & 11,727 & $<0.001$ \\
\hline Total pharmacy costs & 7,004 & 8,685 & 5,300 & 0.213 & 8,018 & 10,247 & 5,737 & $<0.001$ \\
\hline Insulin-related costs & 1,952 & & & & 2,711 & & & \\
\hline Basal & 133 & 422 & 0 & $<0.001$ & 1,196 & 987 & 977 & 0.016 \\
\hline Bolus & 113 & 384 & 0 & - & 1,319 & 1,192 & 1,058 & $<0.001$ \\
\hline Premixed & 1,588 & 1,472 & 1,204 & - & 15 & 183 & 0 & - \\
\hline Insulin administration supplies & 117 & 110 & 97 & $<0.001$ & 181 & 273 & 117 & $<0.001$ \\
\hline SMBG-related costs & 520 & & & & 971 & & & \\
\hline BG testing strips & 501 & 436 & 394 & $<0.001$ & 942 & 794 & 774 & $<0.001$ \\
\hline Other BG testing supplies & 19 & 43 & 0 & - & 29 & 236 & 0 & - \\
\hline Insulin + SMBG-related costs & 2,472 & & & & 3,682 & & & \\
\hline Oral antidiabetic medications & 498 & 842 & 95 & $<0.001$ & 267 & 658 & 0 & $<0.001$ \\
\hline Other NDC pharmacy & 3,387 & 4,994 & 2,154 & 0.249 & 3,319 & 5,858 & 1,563 & $<0.001$ \\
\hline Other HCPCS pharmacy & 646 & 6,151 & 0 & - & 751 & 7,316 & 0 & - \\
\hline Total outpatient costs & 7,993 & 18,285 & 3,505 & 0.511 & 8,538 & 20,160 & 3,825 & $<0.001$ \\
\hline Emergency room visits & 408 & 1,381 & 0 & - & 409 & 1,430 & 0 & - \\
\hline Insulin injections & 1 & 38 & 0 & - & 1 & 40 & 0 & - \\
\hline BG testing lab/clinics & 8 & 224 & 0 & - & 10 & 83 & 0 & - \\
\hline BG testing strips/supplies & 4 & 26 & 0 & - & 6 & 98 & 0 & - \\
\hline Insulin administration supplies & 68 & 669 & 0 & - & 333 & 1,471 & 0 & - \\
\hline Alc lab testing & 35 & 47 & 25 & $<0.001$ & 46 & 57 & 33 & $<0.001$ \\
\hline \multicolumn{9}{|l|}{ Outpatient management visits } \\
\hline FP/GP/Internal medicine & 417 & 1,028 & 276 & 0.018 & 408 & 1,287 & 224 & $<0.001$ \\
\hline Endocrinology & 94 & 225 & 0 & - & 153 & 268 & 0 & - \\
\hline Other/Unknown & 1,149 & 5,620 & 515 & 0.751 & 1,192 & 5,115 & 554 & $<0.001$ \\
\hline Laboratory and pathology & 520 & 2,387 & 200 & $<0.001$ & 621 & 1,712 & 241 & $<0.001$ \\
\hline Radiology & 885 & 2,570 & 143 & 0.642 & 991 & 3,530 & 106 & $<0.001$ \\
\hline Surgical services & 896 & 2,264 & 56 & - & 959 & 3,107 & 0 & - \\
\hline Ancillary services & 3,507 & 14,010 & 662 & 0.364 & 3,409 & 15,575 & 597 & 0.578 \\
\hline Total inpatient costs & 6,575 & 26,405 & 0 & - & 6,565 & 30,196 & 0 & - \\
\hline
\end{tabular}

Initial exploratory analyses of blood glucose test-related claims stratified by specific health plans showed highly variable utilization rates, indicating the existence of differential reimbursement structures by plan. Since a large proportion of patients in certain plans had no evidence of blood glucose tests in the follow-up period, even with an insulin-dependent (and at least minimally persistent) cohort, it appeared necessary to supplement the criteria for the analysis as in all likelihood patients collecting their SMBG strips OTC would have zero claims. It is also important to note that perhaps some of these patients who do not have any insurance claims do not test their blood glucose at all, which would cause this study to overestimate the cost of testing. The Centers for Disease Control and
Prevention (CDC) Behavioral Risk Factor Surveillance System estimated that $87 \%$ of insulin-dependent patients engaged in SMBG on a daily basis. ${ }^{21}$ In order to focus on patients with at least some blood glucose testing, the present study was limited to patients who had at least 1 pharmacy claim for blood glucose testing strips in the post-index period. As our analysis cannot account for OTC use of SMBG strips, nor differentiate patients who do not test from those who use OTC tests, the extent of these additional economic costs remains unknown.

In light of the fact that the economic impact of health plan costs related to blood glucose monitoring for insulin therapy has not been previously measured relative to the total insulin and SMBG-related pharmacy costs, both commercial 


\section{FIGURE 3 12-Month Mean Pharmacy-Based Blood Glucose Testing Claim Costs and Total Insulin} Prescription Costs for Patients with Plan-Covered Test Strip Use by Insulin Regimen ${ }^{\mathrm{b}}$

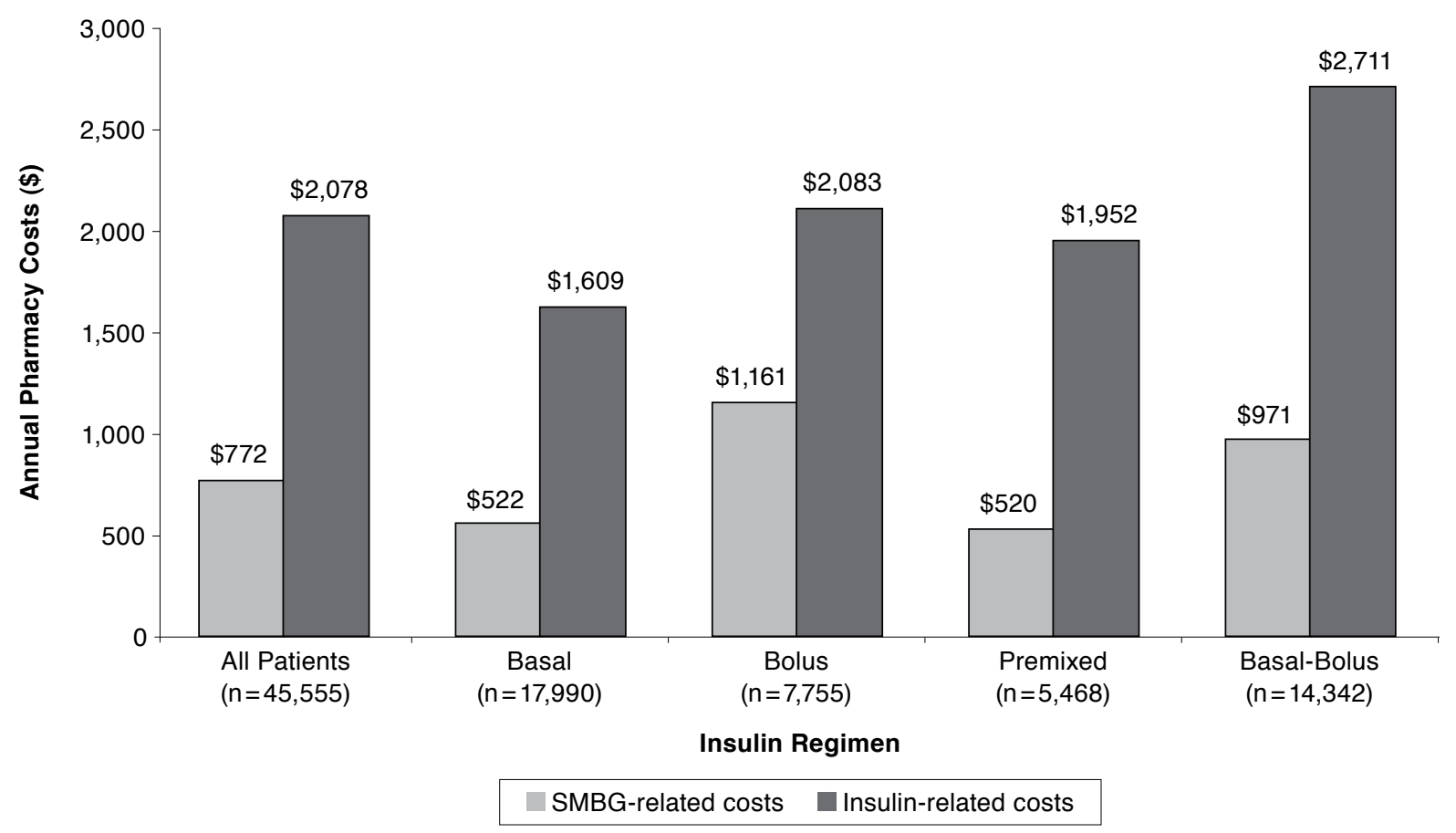

aSMBG-related costs include both testing strips and related supplies, while insulin-related costs include both treatment and administration-related supplies.

bInsulin type classification was based on the first 30 days post-index.

$S M B G=$ self-monitoring of blood glucose.

payers and patients with diabetes may benefit from a greater understanding of SMBG testing costs in the context of clinical benefits.

\section{Limitations}

First, a subset of the diabetic patient population may obtain blood glucose testing strips through nonplan-reimbursed sources, such as OTC or retail mail order providers. Although additional information on the variability of plan reimbursement for SMBG supplies is not currently known, further study may uncover reasons for patients seeking SMBG products through other channels. Second, it should also be noted that a subset of patients in the bolus insulin regimen may have been using insulin pumps, and adjustment for pumps users was not incorporated into the analysis. Third, to the extent that patients switched their insulin type during the followup period, a portion of patients in this study may potentially be misclassified according to therapy type. Those potential misclassifications can be inferred from the patient counts of insulin types other than the index insulin type used for the classification. For example, up to $19 \%$ of patients in the basal insulin group were potentially misclassified because patients with type 1 diabetes normally would require an insulin regimen with meal-time coverage.

Fourth, outpatient blood glucose testing may have been slightly underestimated as some glucose tests might have been bundled into a claim for a test panel (e.g., comprehensive metabolic panel) and therefore not captured with codes for outpatient blood glucose test claims. Fifth, claims for pharmacy blood glucose testing may have been overestimated due to the exclusion of patients with zero claims. Among these patients, this study cannot distinguish between patients who obtain their test strips outside of their health plan and patients who do not test their blood glucose levels. Patients with zero claims may have been following ADA guidelines for nonpump singleinjection insulin patients, which suggest SMBG as an option rather than a requirement., ${ }^{5,6}$ As this study assumed full use of testing strips by the patients who received the prescription, additional overestimation is possible in cases of unused strips or resale of supplies to other individuals. 


\section{Conclusion}

For insulin users with at least 1 pharmacy claim for glucose test strips, SMBG accounts for about one-fourth of insulin and SMBG-related pharmacy costs.

\section{Authors}

JASON YEAW, MPH, is Director, Health Economics and Outcomes Research, and WON CHAN LEE, PhD, is Principal, IMS Consulting Group, Alexandria, Virginia. MARK AAGREN, MSc, is Head of Health Economics, Novo Nordisk, Virum, Denmark, and TORSTEN CHRISTENSEN, PhD, is Project Lead, Novo Nordisk, Copenhagen, Denmark.

AUTHOR CORRESPONDENCE: Jason Yeaw, MPH, Health Economics and Outcomes Research, IMS Consulting Group, 3 Lagoon Dr., Ste. 230, Redwood City, CA 94065. Tel : 650.226.4114;

E-mail: jyeaw@imscg.com.

\section{DISCLOSURES}

This study was sponsored by Novo Nordisk, and 2 of the authors (Aagren and Christensen) are employees of Novo Nordisk. Novo Nordisk was involved in the concept, data interpretation, revision, and approval of the manuscript.

The study was conceived and designed by the 4 authors. Yeaw interpreted the data, wrote and revised the manuscript, with the assistance of Aagren, Lee, and Christensen.

\section{ACKNOWLEDGEMENT}

The authors thank Paula Smith, MS, Analytic Programmer, IMS Consulting Group, who collected the data with the assistance of Yeaw.

\section{REFERENCES}

1. International Diabetes Federation. IDF diabetes atlas. 5th ed. October 2011. Available at: http://www.diabetesatlas.org/content/diabetes-andimpaired-glucose-tolerance. Accessed December 17, 2011.

2. International Diabetes Federation. IDF diabetes atlas: healthcare expenditures. 5th ed. October 2011. Available at: http://www.idf.org/ diabetesatlas/5e/healthcare-expenditures. Accessed December 17, 2011.

3. Clar C, Barnard K, Cummins E, Royle P, Waugh N; Aberdeen Health Technology Assessment Group. Self-monitoring of blood glucose in type 2 diabetes: systematic review. Health Technol Assess. 2010;14(12):1-140.

4. Canadian Diabetes Association. 2008 clinical practice guidelines for the prevention and management of diabetes in Canada. Can J Diabetes. 2008;32(Suppl 1):i-S201. Available at: http://www.diabetes.ca/files/cpg2008/ cpg-2008.pdf. Accessed December 17, 2011.

5. American Diabetes Association. Standards of medical care in diabetes-2010. Diabetes Care. 2010;33(Suppl 1):S11-S61. Available at: http://care. diabetesjournals.org/content/33/Supplement_1/S11.full.pdf+html. Accessed December 17, 2011.

6. American Diabetes Association. Standards of medical care in diabetes-2011. Diabetes Care. 2011;34(Suppl 1):S11-S61. Available at: http://care. diabetesjournals.org/content/34/Supplement_1/S11.full.pdf+html. Accessed December 17, 2011.

7. Rodbard HW, Blonde L, Braithwaite SS, et al.; AACE Diabetes Mellitus Clinical Practice Guidelines Task Force. American Association of Clinical Endocrinologists medical guidelines for clinical practice for the management of diabetes mellitus. Endocr Pract. 2007;13(Suppl 1):S1-S68.

8. International Diabetes Federation. Guideline for management of postmeal glucose. 2007. Available at: http://www.idf.org/webdata/docs/Guideline_ PMG_final.pdf. Accessed December 17, 2011.

9. Glasgow RE, Wagner EH, Kaplan RM, Vinicor F, Smith L, Norman J. If diabetes is a public health problem, why not treat it as one? A populationbased approach to chronic illness. Ann Behav Med. 1999;21(2):159-70.

10. Karter AJ, Ferrara A, Darbinian JA, Ackerson LM, Selby JV. Selfmonitoring of blood glucose: language and financial barriers in a managed care population with diabetes. Diabetes Care. 2000;23(4):477-83.

11. Tu KS, Barchard K. An assessment of diabetes self-care barriers in older adults. J Community Health Nurs. 1993;10(2):113-18.

12. Sandeep Vijan, Hayward RA, Ronis DL, Hofer TP. Brief report: the burden of diabetes therapy: implications for the design of effective patientcentered treatment regimens. J Gen Intern Med. 2005;20(5):479-82.

13. American Diabetes Association. Economic costs of diabetes in the U.S. in 2007. Diabetes Care. 2008;31(3):596-615. Available at: http://care.diabetesjournals.org/content/31/3/596.full. Accessed December 17, 2011.

14. Pollock RF, Valentine WJ, Goodall G, Brändle M. Evaluating the costeffectiveness of self-monitoring of blood glucose in type 2 diabetes patients on oral anti-diabetic agents. Swiss Med Wkly. 2010;140:wl3103. Available at: http://www.smw.ch/content/smw-2010-13103/. Accessed December 17, 2011.

15. Kjome RL, Granas AG, Nerhus K, Roraas TH, Sandberg S. The prevalence of self-monitoring of blood glucose and costs of glucometer strips in a nationwide cohort. Diabetes Technol Ther. 2010;12(9):701-05.

16. Weber C, Kocher S, Neeser K, Bartaskova D. Impact of self-measurement of blood glucose on complications of type 2 diabetes: economic analysis from a Czech perspective. Curr Med Res Opin. 2010;26(2):289-96.

17. Neeser K, Weber C. Cost impact of self-measurement of blood glucose on complications of type 2 diabetes: the Spanish perspective. Diabetes Technol Ther. 2009;11(8):509-16.

18. Bonafede MMK, Kalsekar A, Pawaskar M, Ruiz KM, Torres AM, Kelly KR, Curkendall SM. A retrospective database analysis of insulin use patterns in insulin-naive patients with type 2 diabetes initiating basal insulin or mixtures. Patient Prefer Adherence. 2010;4:147-56. Available at: http:// www.ncbi.nlm.nih.gov/pmc/articles/PMC2898116/?tool=pubmed. Accessed December 17, 2011.

19. Romano PS, Roos LL, Jollis JG. Adapting a clinical comorbidity index for use with ICD-9-CM administrative data: differing perspectives. J Clin Epidemiol. 1993;46(10):1075-79.

20. U.S. Department of Labor. Bureau of Labor Statistics. U.S. consumer price index-all urban consumers. Medical care 1982-84. Available at: http://data.bls.gov/cgi-bin/surveymost?cu. Accessed December 17, 2011.

21. Centers for Disease Control and Prevention. Self-monitoring of blood glucose among adults with diabetes-United States, 1997-2006. MMWR Morb Mort Wkly Rep. 2007;58(43):1133-77. Available at: http://www.cdc.gov/ $\mathrm{mmwr} /$ preview/mmwrhtml/mm5643a3.htm. Accessed December 17, 2011. 


\section{APPENDIX A Codes for Insulin and Related Supplies, Oral Antidiabetic Medications,} and Blood Glucose Testing

\begin{tabular}{|c|c|c|}
\hline Insulin Type & Product & GPI Codes ${ }^{a}$ \\
\hline \multirow[t]{5}{*}{ Basal (long acting) } & LANTUS & 27104003 \\
\hline & LEVEMIR & 27104006 \\
\hline & HUMULIN NPH & 27104020001805 and brand name starts with "Humulin" \\
\hline & NOVOLIN NPH & 27104020001805 and brand name starts with "Novolin" \\
\hline & OTHER BASAL & $\begin{array}{l}27101020,27101040,27102040,27103020,27103040,27104020 \text { (exclud- } \\
\text { ing Humulin NPH and Novolin NPH above), 27104030, } 27101050 \text {, } \\
27101030,27102030,27102050,27103030,27104050,27102020\end{array}$ \\
\hline \multirow{5}{*}{$\begin{array}{l}\text { Premixed insulin (short- } \\
\text { and long-acting fixed } \\
\text { combination) }\end{array}$} & HUMALOG 75/25 & 27104080 \\
\hline & NOVOLOG 70/30 & 27104070 \\
\hline & HUMULIN 70/30 & 27104090 and brand name starts with "Humulin" \\
\hline & NOVOLIN 70/30 & 27104090 and brand name starts with "Novolin" \\
\hline & OTHER MIXTURE & $\begin{array}{l}27103070,27104090 \text { (excluding Novolog } 70 / 30 \text { and Humulin 70/30 } \\
\text { above) }\end{array}$ \\
\hline \multirow[t]{6}{*}{ Bolus only (short acting) } & HUMALOG & 27104005 \\
\hline & NOVOLOG & 27104002 \\
\hline & APIDRA & 27104004 \\
\hline & HUMULIN R & 27104010002005 and brand name starts with "Humulin" \\
\hline & NOVOLIN R & 27104010002005 and brand name starts with "Novolin" \\
\hline & OTHER RAPID HUMAN & $\begin{array}{l}\text { 27101010, 27101060, 27102010, 27102060, 27103010, } 27103060, \\
27104010 \text { (excluding Humulin R and Novolin R above), } 27104015\end{array}$ \\
\hline Insulin-Related Supplies & CPT-4 or HCPCS Codes & GPI Codes ${ }^{a}$ \\
\hline Needles/syringes & S8490 & $97051030056,9705103010,9705103040,9705103090,9705105020$ \\
\hline Insulin pen and pen needles & S5560, S5561, S5570, S5571 & 9705105012,9705105014 \\
\hline $\begin{array}{l}\text { Insulin pump and other } \\
\text { insulin administration } \\
\text { supplies }\end{array}$ & $\begin{array}{l}\text { E0781, E0784, A4231, A4230, K0552, S5565, } \\
\text { S5566, A4221, A4232, E0781, E0784, J1817, } \\
\text { A4632, K0601-K0605, A4365, A5120, A4245, } \\
\text { A4247, A6257, A6258, A4364, A4450, A9274 }\end{array}$ & 972010 \\
\hline Oral Antidiabetic Drug & Generic Name & GPI Codes ${ }^{a}$ \\
\hline Thiazolidinediones & pioglitazone $\mathrm{HCL}$, rosiglitazone maleate & 27607060,27607050 \\
\hline Sulfonylureas & $\begin{array}{l}\text { glimepiride, glyburide (includes micronized), } \\
\text { glipizide, other (acetohexamide, } \\
\text { chlorpropamide, tolazamide, tolbutamide) }\end{array}$ & 2720 \\
\hline Biguanides & metformin & 2725 \\
\hline Meglitinides & repaglinide, nateglinide & 2728 \\
\hline Alpha-glucosidase inhibitors & acarbose, miglitol & 2750 \\
\hline $\begin{array}{l}\text { Sulfonylurea-metformin } \\
\text { fixed-dose combination }\end{array}$ & glipizide-metformin, glyburide-metformin & 279970 \\
\hline $\begin{array}{l}\text { Thiazolidinedione-metformin } \\
\text { fixed-dose combination }\end{array}$ & $\begin{array}{l}\text { pioglitazone HCL-metformin, rosiglitazone } \\
\text { maleate-metformin }\end{array}$ & 279980 \\
\hline $\begin{array}{l}\text { Sulfonylurea- } \\
\text { thiazolidinedione fixed-dose } \\
\text { combination }\end{array}$ & $\begin{array}{l}\text { glimepiride-rosiglitazone, glimepiride- } \\
\text { pioglitazone }\end{array}$ & 279978 \\
\hline DPP-4 inhibitor & sitagliptin, saxagliptin & 27550070,27550065 \\
\hline $\begin{array}{l}\text { Meglitinides-metformin } \\
\text { fixed-dose combination }\end{array}$ & repaglinide-metformin & 279950 \\
\hline $\begin{array}{l}\text { DPP-4 inhibitor-metformin } \\
\text { fixed-dose combination }\end{array}$ & sitagliptin-metformin & 279925 \\
\hline Bile acid sequestrant & colesevelam & 39100016 \\
\hline
\end{tabular}

aThe Medi-Span GPI is 14 characters in length; values less than 14 characters indicate that GPI codes beginning with this sequence were included. CPT-4 = Current Procedural Terminology, Fourth Edition; DPP = dipeptidyl peptidase; GPI = generic product identifier; HCPCS = Healthcare Common Procedure Coding System. 
APPENDIX A Codes for Insulin and Related Supplies, Oral Antidiabetic Medications, and Blood Glucose Testing (continued)

\begin{tabular}{|c|c|c|}
\hline Blood Glucose Testing & CPT-4 or HCPCS Code & GPI Codes ${ }^{a}$ \\
\hline $\begin{array}{l}\text { Outpatient clinic or } \\
\text { laboratory/diagnostic blood } \\
\text { glucose testing procedures }\end{array}$ & $\begin{array}{l}82945,82947,82948,82950,82951,82952, \\
95250,95251, \text { A9276, A9277, A9278, S1030, } \\
\text { S1031 }\end{array}$ & \\
\hline Pharmacy-testing strips & & $94100030006100,94100030009800,94100030006000$ \\
\hline Medical-testing strips & A4253 & \\
\hline $\begin{array}{l}\text { Other blood glucose testing } \\
\text { supplies-glucose meters, } \\
\text { lancet device and lancets, } \\
\text { control solution, logbooks }\end{array}$ & $\begin{array}{l}\text { A4259, A4258, E0609, E2100, E2101, 82962, } \\
\text { A9275 }\end{array}$ & $972020,972025,972030,972040$ \\
\hline
\end{tabular}

\section{APPENDIX B Diabetes Types ${ }^{a}$}

\begin{tabular}{l|l}
\hline Diagnosis & ICD-9-CM, GPI,, and HCPCS/J Codes \\
\hline Type 1 diabetes & At least 2 claims with ICD-9-CM codes (250.xl or \\
& 250.x3) AND at least 1 claim for GPI 2710 OR HCPCS/ \\
& ICD-9-CM codes (E0784, J1817, V53.91) \\
\hline Type 2 diabetes & $\begin{array}{l}\text { At least } 2 \text { claims with ICD-9-CM codes (250.x0 or } \\
\text { 250.x2) AND at least 1 claim for GPI 27 excluding 2730 }\end{array}$ \\
\hline
\end{tabular}

${ }^{a}$ Measured during the 6-month pre-index and/or 12-month post-index periods.

${ }^{b}$ The Medi-Span GPI is 14 characters in length; values less than 14 characters indicate that GPI codes beginning with this sequence were included.

GPI = generic product identifier; HCPCS = Healthcare Common Procedure Coding

System; ICD-9-CM = International Classification of Diseases, Ninth Revision,

Clinical Modification; J =injection. 